\title{
Mandibular Central Mucoepidermoid Carcinoma: A Case Report and Review of the Literature
}

\author{
Ilson Sepúlveda ${ }^{a, f} \quad$ Michael Frelinghuysen $^{b} \quad$ Enrique Platin $^{g}$ \\ M. Loreto Spencer ${ }^{d} \quad$ Alvaro Compan $^{\mathrm{a}}$ Juan Munzenmayer ${ }^{c}$ \\ David Ulloa \\ ${ }^{a}$ ENT-Head and Neck Surgery Service, ${ }^{b}$ Radiotherapy Unit of Oncology Service, ${ }^{c}$ Dental \\ Service, and ${ }^{\mathrm{d}}$ Pathology Department, General Hospital of Concepción, and ${ }^{e}$ Private \\ Practice, Concepción, and fFinis Terrae University, School of Dentistry, Santiago, Chile; \\ ${ }^{9}$ Department of Oral and Maxillofacial Radiology, University of North Carolina School of \\ Dentistry, Chapel Hill, N.C., USA
}

\section{Key Words}

Computed tomography $\cdot$ Mandible $\cdot$ Tumor

\begin{abstract}
We report the case of a patient whose main complaint was swelling on the right side of the mandible when he presented to the Ear, Nose and Throat (ENT) Service. Imaging studies revealed a large homogeneous, multilocular, expansive lesion in the body of the right mandibular ramus. The lesion was poorly enhanced following intravenous contrast injection. The patient was treated with hemimandibular surgical resection, fibula free flap reconstruction and adjuvant radiotherapy. Currently, the patient is disease free and free of posttreatment complications.

(c) 2014 S. Karger AG, Basel
\end{abstract}

\section{Case Report}

A 42-year-old male without a significant medical history presented to the Ear, Nose and Throat (ENT) Service complaining of right mandibular swelling of several years' duration. A clinical exam revealed multiple root fragments and swelling on the right side of the mandible.

A computed tomography (CT) exam was performed revealing a large, homogeneous, expansive, multilobular process with cystic appearance in the body of the right mandibular 
ramus (fig. 1, fig. 2, fig. 3, fig. 4). Also, intravenous contrast medium administration resulted in poor enhancement of the lesion, showing expansion and bone erosion and displacement of adjacent masticatory muscles (fig. 5). Due to the size mass, a slight displacement of the ipsilateral parapharyngeal space and airway was noted. There was no evidence of morphological or density changes of the submaxillary glands. In addition, nonspecific lymphadenopathy was detected at ganglionic levels IB, IIA, IIB and V.

This case was reviewed by the Head and Neck Surgical Board (HNSB), where a hemimandibular surgical resection accompanied by fibula free flap reconstruction was recommended as the treatment of choice.

A postsurgical biopsy revealed the presence of fibrous fragments infiltrated by 'mucoepidermoid carcinoma' (MEC) with micrometastases and positive margins. The sample included muscle tissues infiltrated by the tumor (fig. 6).

The patient was followed up by the HNSB and adjuvant complementary radiotherapy was recommended. The interdisciplinary team is currently following the patient, with no evidence of tumor being detected so far.

\section{Discussion}

Salivary gland tumors are relatively uncommon neoplasms [1]. MEC is a malignant neoplasm of the salivary gland first described in 1945 [2]. It accounts for 5-10\% of all salivary gland tumors; $86 \%$ mainly involve the parotid gland, followed by $8 \%$ involving the submandibular gland and $4 \%$ the sublingual glands. The minor salivary glands found in the palate is the next most common site for these tumors [3-5]. The frequency of these tumors has been known to increase in patients who were previously treated with radiotherapy [6].

MECs occur more commonly in women, with the highest incidence observed between the third and sixth decades of life; however, they may be detected at any age [7]. Approximately $3-10 \%$ of the affected patients are in their first and second decades of life [1]. As in other tumors, the usual symptoms are related to the location of the primary tumor, infiltration of the surrounding structures, the presence of cervical lymph nodes and distant metastases. Nasal obstruction, bleeding, headaches, facial numbness, tinnitus or hearing loss, deafness and diplopia are the most common clinical symptoms [8].

MEC is histologically made up of epidermoid and mucin-producing cells originating in the ducts of the epithelial lining [9]. Histologically, the tumor is classified into three grades: low, intermediate and high. Herd et al. [10] performed a study of 546 patients and reported that the distribution of intraoral MECs was high in 58.4\%, intermediate in $38.3 \%$ and low in $3.2 \%$.

Central MEC is extremely rare making up 2-3\% of all MECs reported. This tumor is characterized by atypical clinical and radiographic appearances [11]. The lower jaw is affected in $82 \%$ of the cases, with $83 \%$ occurring in the molar region, the most probable location for developing dentigerous cysts and odontogenic tumors [12].

The criteria for the diagnosis of central MEC include cortical bone void of perforation by tumor invasion, radiological evidence of bone destruction, and histopathological verification [13]. Radiographic expression of central MEC consistently shows bone destructionwith a multilocular or cystic-like radiolucent appearance. Also, this tumor has the potential to form hard tissue and be expressed as a mixed lesion [2]. The rate of metastases for high-grade tumors is $55 \%$ for the major glands and $80 \%$ for those originating in the minor salivary glands [6]. The incidence of regional lymph node metastases has been reported to be between 2.5 and $20 \%$ [14]. 
The preferred treatment of choice is wide surgical resection, with clear margins. Postoperative radiotherapy is recommended for high-grade tumors with positive margins or regional lymph involvement [15]. Pediatric salivary gland MECs have a good prognosis, and low- to intermediate-grade early-stage tumors should be treated with surgery alone. Neck dissection should be performed in high-grade tumors followed by radiotherapy to the affected area. For high-grade tumors without massive neck involvement, radiation may be limited to the primary affected region given the risk of the long-term side effects of radiotherapy in children [16].

Tumor grade is considered the most important prognostic factor in salivary gland MECs, worsening in survival rates from low to high [17]. High-grade tumors have a greater tendency to infiltrate, recur and metastasize with reported cure rates of 49 and $42 \%$ at 5 and 10 years, respectively [6].

\section{Conclusion}

MEC is a malignant neoplasm of the salivary gland, with the ability to metastasize and relapse locally. It affects women more commonly, with the highest incidence occurring between the third and sixth decades of life. Central MEC is exceedingly rare, constituting only 2-3\% of all MECs reported. Imaging features include bone destruction with a multilocular or cyst-like radiolucent appearance. The treatment of choice is complete surgical excision of the affected region accompanied by radiotherapy when clear margins are not attained and there is nodal involvement.

\section{Disclosure Statement}

The authors have no conflicts of interest to disclose.

\section{References}

1 Perez DE, Pires FR, Alves Fde A, Lopes MA, de Almeida OP, Kowalski LP: Juvenile intraoral mucoepidermoid carcinoma. J Oral Maxillofac Surg 2008;66:308-311.

-2 Johnson B, Velez I: Central mucoepidermoid carcinoma with an atypical radiographic appearance. Oral Surg Oral Med Oral Pathol Oral Radiol Endod 2008;106:51-53.

-3 Verma RK, Sunku SK, Bal A, Panda NK: Giant cystic primary mucoepidermoid carcinoma of mandible: a rare case and literature review. Otolaryngol Polska DOI: 10.1016/j.otpol.2013.11.004.

-4 Garcia-Molina D, Del Castillo J, Navarro I, Sánchez R, Burgueño M: Carcinoma mucoepidermoide de bajo grado. Diagnóstico diferencial de masas palatinas. Rev Esp Cir Oral Maxilofac 2014;36:136-138.

5 Zhang X, et al: Nasopharyngeal mucoepidermoid carcinoma: a review of 13 cases. Oral Oncol 2010;46:618621.

6 Woo H-J, et al: Mucoepidermoid carcinoma of the submandibular gland after chemotherapy in a child. Auris Nasus Larynx 2009;36:244-246.

-7 Tamaki S, et al: Low grade mucoepidermoid carcinoma of the maxillary tuberosity: a case report. Asian J Oral Maxillofac Surg 2011;23:42-45.

8 Martinez J, et al: Nasopharyngeal mucoepidermoid carcinoma: a case report and review of literature. Rep Pract Oncol Radiother 2013;18:117-120.

-9 Abdel-Aziz M: Mucoepidermoid carcinoma of the tongue in a child. Int J Pediatr Otorhinolaryngol Extra 2012;7:6-8.

10 Herd K, et al: Low-grade mucoepidermoid carcinoma of the palate - a previously unreported case of metastasis to the liver. J Oral Maxillofac Surg 2012;70:2343-2346.

$\checkmark 11$ He Y, et al: Intraosseous mucoepidermoid carcinoma of jaws: report of 24 cases. Oral Surg Oral Med Oral Pathol Oral Radiol 2012;114:424-429. 


\section{Case Reports in Oncology}

\begin{tabular}{l|l}
\hline Case Rep Oncol 2014;7:732-738 & \\
\hline DOI: $10.1159 / 000368825$ & $\begin{array}{l}\text { ○ 2014 S. Karger AG, Basel } \\
\text { www.karger.com/cro }\end{array}$ \\
\hline
\end{tabular}

Sepúlveda et al:: Mandibular Central Mucoepidermoid Carcinoma: A Case Report and Review of the Literature

12 Dain CP, et al: Central mucoepidermoid carcinoma of the mandible - from a histopathologic perspective. J Oral Maxillofac Surg Med Pathol, in press.

13 de Mello-Filho FV, et al: Central mucoepidermoid carcinoma: report of 2 cases. Br J Oral Maxillofac Surg 2008;46:239-241.

14 Chiu GA, et al: Mandibular central mucoepidermoid carcinoma with distant metastasis. Int J Oral Maxillofac Surg 2012;41:361-363.

15 Vila Masana I, et al: Mucoepidermoid carcinoma of the sublingual gland: presentation of a case. Rev Esp Cir Oral Maxilofac 2012;34:133-139.

16 Thariat J, et al: The role of radiation therapy in pediatric mucoepidermoid carcinomas of the salivary glands. J Pediatr 2013;162:839-843.

17 Liu S, et al: Prognostic factors in primary salivary gland mucoepidermoid carcinoma: an analysis of 376 cases in an Eastern Chinese population. Int J Oral Maxillofac Surg 2014;43:667-673.

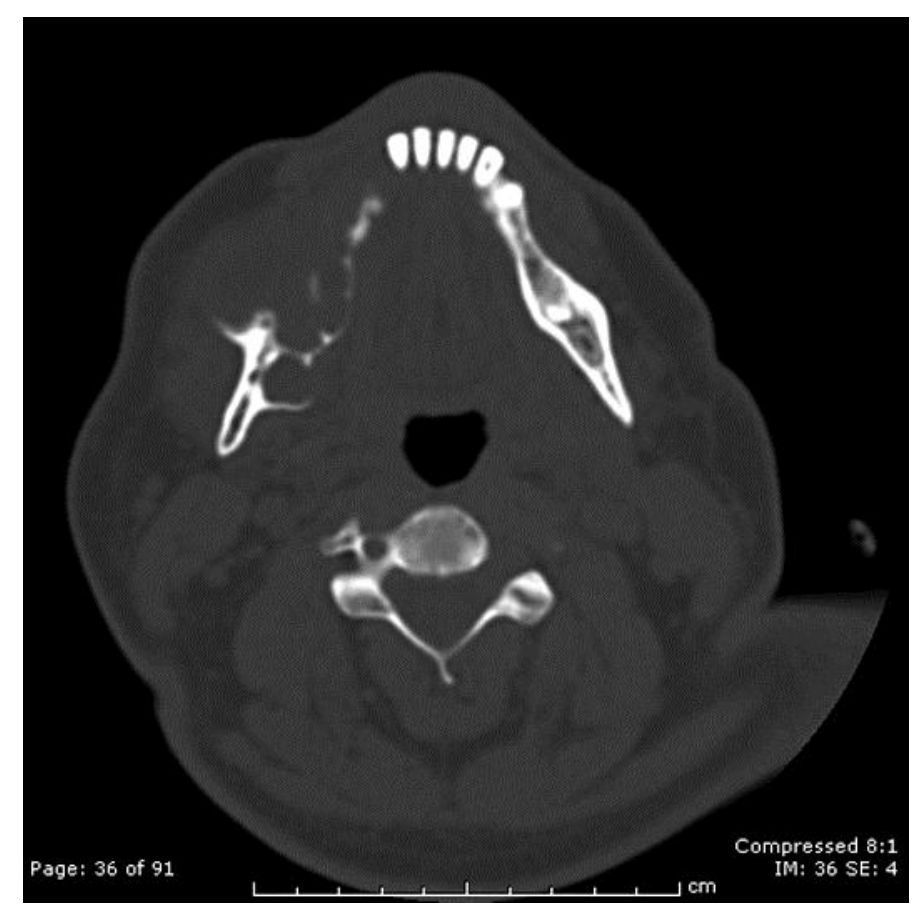

Fig. 1. Axial CT showing an expansive, multilocular process in the right mandibular ramus. 


\section{Case Reports in Oncology}

\begin{tabular}{l|l}
\hline Case Rep Oncol 2014;7:732-738 & \\
\hline DOI: $10.1159 / 000368825$ & $\begin{array}{l}\text { () 2014 S. Karger AG, Basel } \\
\text { www.karger.com/cro }\end{array}$ \\
\hline
\end{tabular}

Sepúlveda et al:: Mandibular Central Mucoepidermoid Carcinoma: A Case Report and Review of the Literature

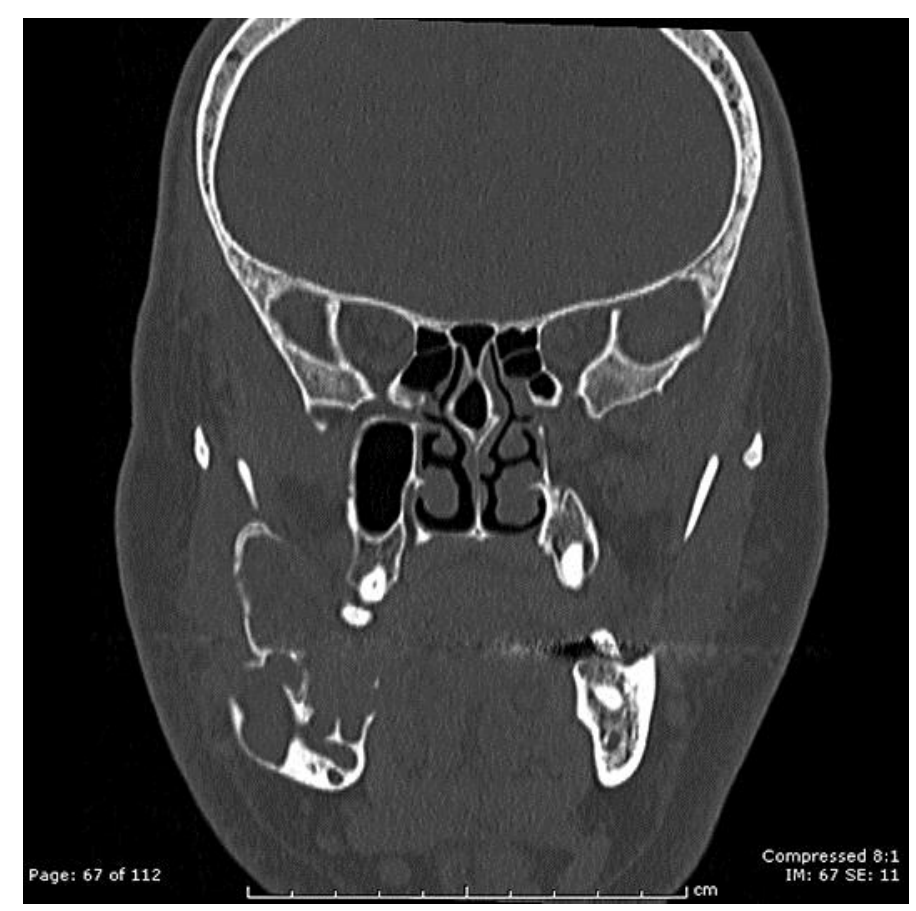

Fig. 2. Coronal CT demonstrates a large expansive process in the right mandibular ramus.

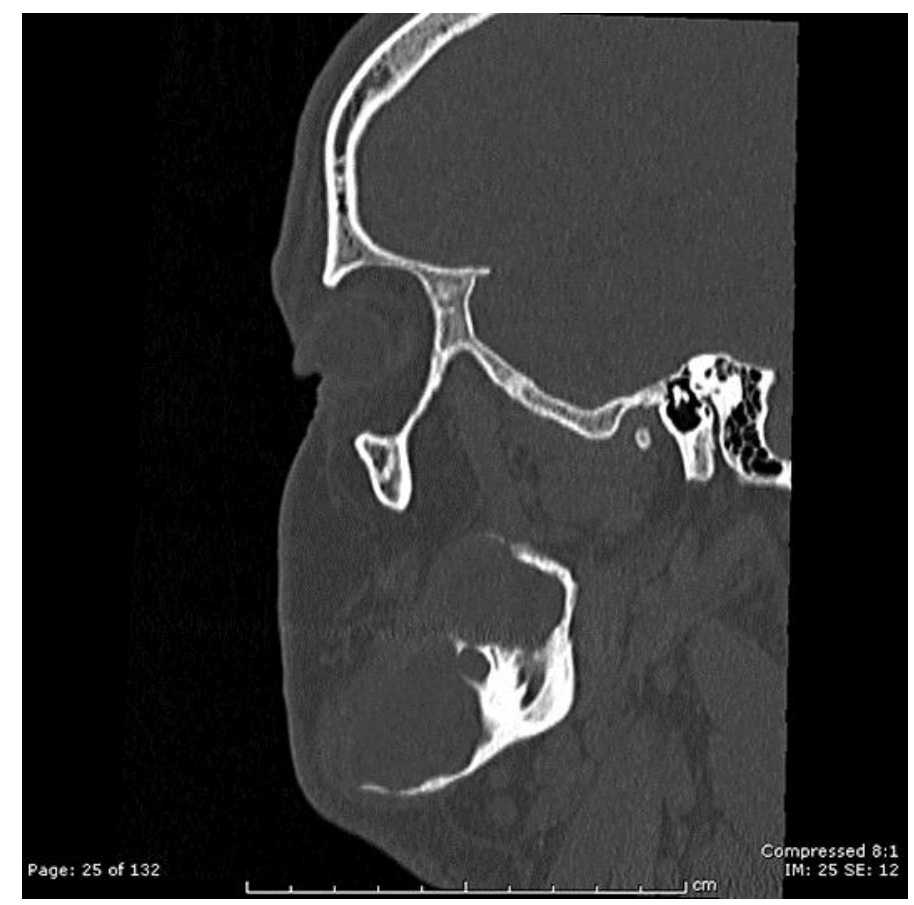

Fig. 3. Sagittal CT shows erosion of the cortical bone in the right mandibular ramus. 


\section{Case Reports in Oncology}

\begin{tabular}{l|l}
\hline Case Rep Oncol 2014;7:732-738 & \\
\hline DOI: $10.1159 / 000368825$ & $\begin{array}{l}@ \text { 2014 S. Karger AG, Basel } \\
\text { www.karger.com/cro }\end{array}$ \\
\hline
\end{tabular}

Sepúlveda et al:: Mandibular Central Mucoepidermoid Carcinoma: A Case Report and Review of the Literature

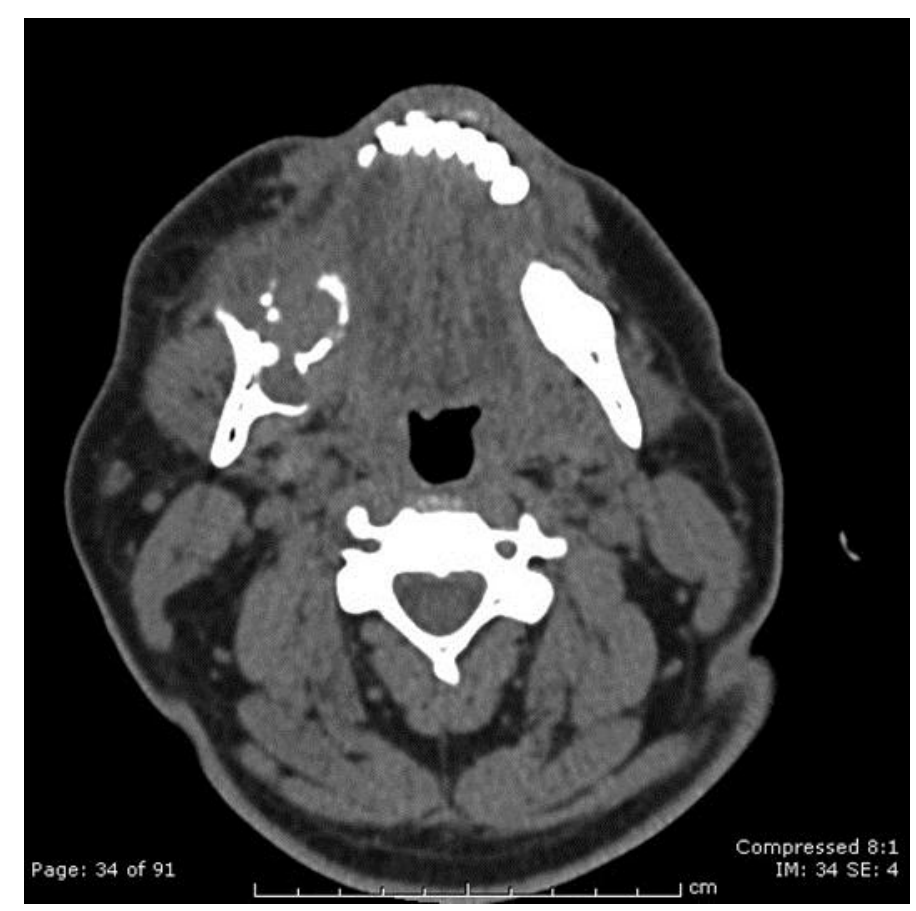

Fig. 4. Soft-tissue window CT demonstrates a cystic-like isodense expansive process.

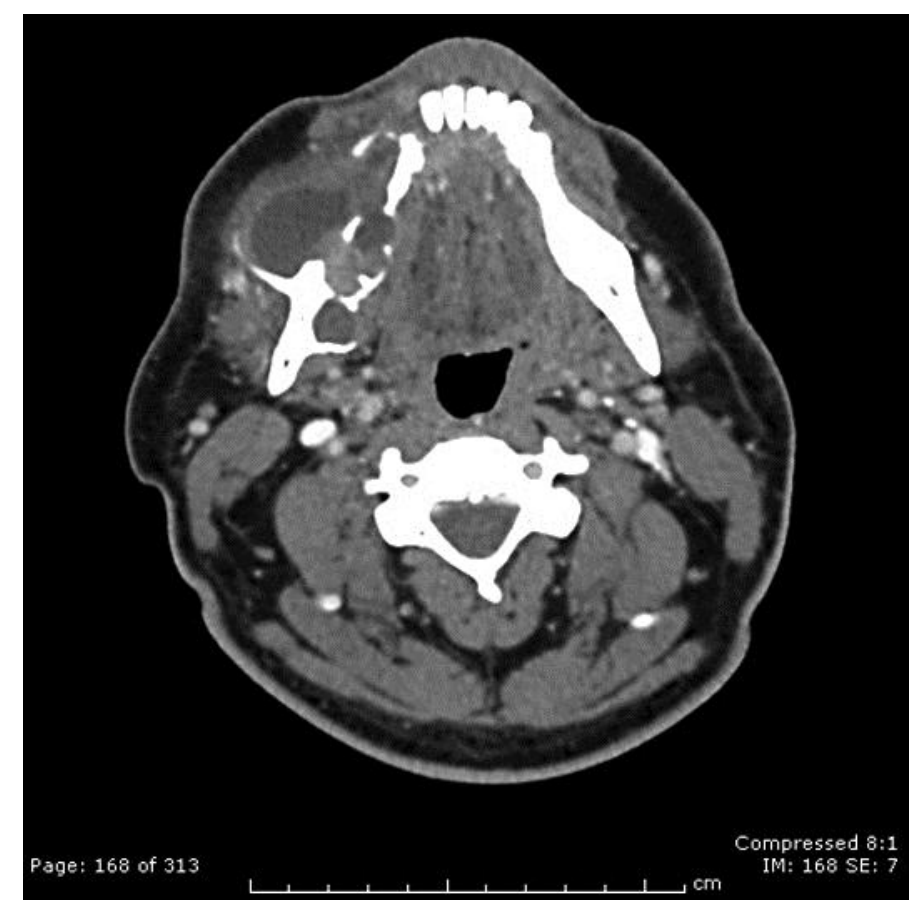

Fig. 5. Soft-tissue window CT following intravenous contrast medium administration shows poor enhancement of the solid component of the mass. Displacement of the masseter muscle is also seen. 


\section{Case Reports in Oncology}

Case Rep Oncol 2014;7:732-738

DOI: $10.1159 / 000368825$

2014 S. Karger AG, Basel

Sepúlveda et al:: Mandibular Central Mucoepidermoid Carcinoma: A Case Report and Review of the Literature

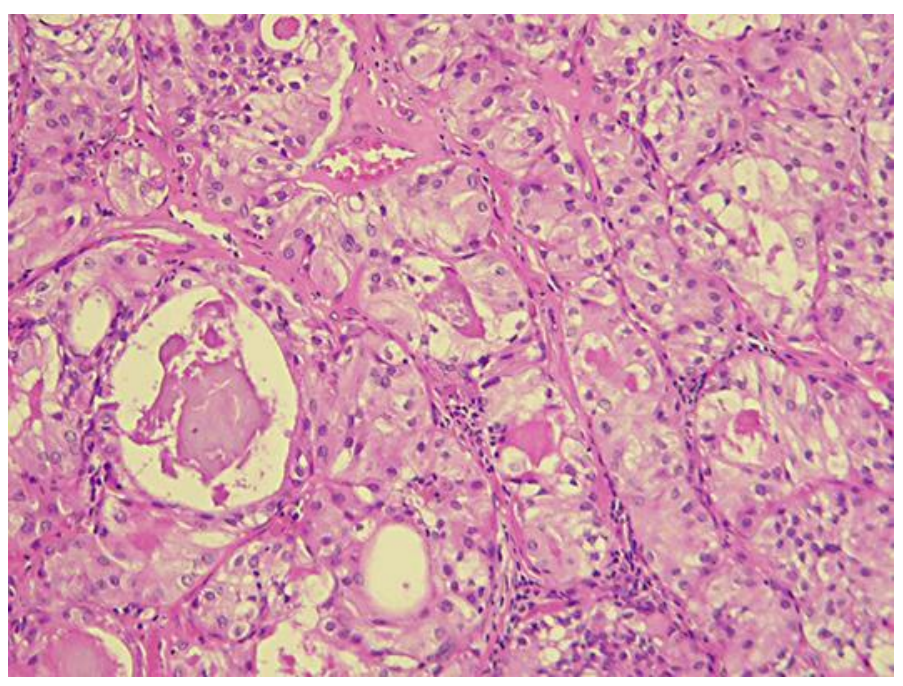

Fig. 6. Muscle tissues infiltrated by the tumor. HE staining. 